\title{
THE EFFECT OF ADDITIONAL GRAPE (Vitis vinifera) OIL AS A SOURCE OF OMEGA-6 ON ALBUMIN POWDER OF FISH (Channa striata) ON Wound Closure
}

\author{
Aisy Azka Ramdhani Yusuf*, Eddy Suprayitno** \\ *Department of Fisheries Technology \\ Faculty of Fisheries and marine science \\ Brawijaya University Indonesia \\ Aisyazka052@student.ub.ac.id \\ **Department of Fisheries Technology \\ Faculty of Fisheries and marine science \\ Brawijaya University Indonesia \\ eddysuprayitno@ub.ac.id \\ DOI: 10.29322/IJSRP.11.12.2021.p12040 \\ http://dx.doi.org/10.29322/IJSRP.11.12.2021.p12040
}

\begin{abstract}
Albumin powder is an alternative development of snakehead fish albumin extract which is useful for wound healing besides albumin powder also reduces fishy taste and is easy to use. One way is to process the powder into using a vacuum drying method with a temperature of $49^{\circ}$. Wound healing is also influenced by several factors other than albumin. Among other things, the role of omega3 , omega-6, and collagen. The results of the first stage of the study showed that different concentrations of grapeseed oil affected the quality of albumin powder including: omega- 6 levels, yield, protein, fat, water, and ash. The best albumin powder is using omega 6 $5 \%$ concentration with the results: omega- 6 content $2.89 \%$, yield $59.18 \%$, protein $4.03 \%$, fat $7.69 \%$, water $2.49 \%$, ash $1,01 \%$. The results of the second stage of the study showed that the highest fatty acid was linoleic acid (2.88\%). Observation of wound closure in mice showed that $5 \%$ omega- 6 concentration was the best with $70 \%$ wound closure. Day 7
\end{abstract}

Keywords- albumin, powder, omega-6, grapeseed oil, wound closure

\section{INTRODUCTION}

One of the wealth of Indonesian fisheries is snakehead fish which has a high nutritional content and albumin content of $6.25 \%$. Albumin is needed by the human body every day, especially in wound healing (Suprayitno., 2014). Wound healing is also influenced by the role of omega 3 , omega 6 , and collagen. Omega- 6 fatty acids from grapeseed oil have a high omega- 6 content of about $66 \%$, which is able to positively modulate all phases of wound healing influencing the inflammatory response and enabling wound healing (Silva et al., 2018).

Snakehead fish albumin extract is usually consumed in liquid form and smells fishy so not everyone likes it. For this reason, another alternative is needed, namely by processing using the drying method so that albumin is produced in powder form which is later expected to be accepted by everyone (Yuniarti, et al., 2013). This study aims to develop processed snakehead fish albumin which is added with omega- 6 from grape seed oil into albumin powder so that it is more efficiently used for wound closure.

\section{Materials and Methods}

\subsection{Materials}


The raw material for albumin comes from snakehead fish (Channa striata). The raw materials for collagen are grouper skin (Ephinephelus sp), acetic acid, $\mathrm{NaOH}$, aquades. The raw materials for the production of albumin powder are albumin extract, collagen, grape seed oil, soybean seed oil, and dextrin, sorbitol, and aquades as fillers.

This study used 2 experimental stages. The first stage aims to obtain the optimal concentration of grapeseed oil added to albumin powder so as to obtain the desired powder quality. Then the second stage aims to observe the wound closure process in experimental animals using the best quality albumin powder compared to negative and positive controls

\subsubsection{Albumin extraction}

Extraction begins with preparing tools and materials. The steamer is placed on the stove, put water in and then the stove is turned on. Wait until it is hot then put in a basin with cork fish on it. The snakehead fish was steamed and the extract was taken as albumin. Snakehead fish meat used as much as 2500 grams, then obtained extract as much as 1130 grams. So that the yield of $45.2 \%$ is obtained.

\subsubsection{Collagen}

The scales of the grouper were removed, then washed, then cut into squares measuring $1 \mathrm{~cm} \times 1 \mathrm{~cm}$. Then the grouper skin is ready to be used for the manufacture of collagen. The grouper skin used was 5000 grams, then 688 grams of collagen were obtained. So that the yield of $13.76 \%$ is obtained.

\subsubsection{Albumin powder}

$180 \mathrm{ml}$ albumin extract was added as filler 75\% dextrin, 25\% sorbitol, omega 3 from soybean seed oil, omega 6 from grape seed oil with concentrations of 3\%, 4\%, and 5\%. It was homogenized using a 1000rpm homogenizer for 30 minutes, then poured into a baking sheet, and put into vacuum drying at a temperature of $49^{\circ} \mathrm{C}$ for 7 hours. The dried samples were then blended and sieved with a size of 60 mesh.

\section{RESULT AND DISCUSSION}

\subsection{Omega-6 Content}

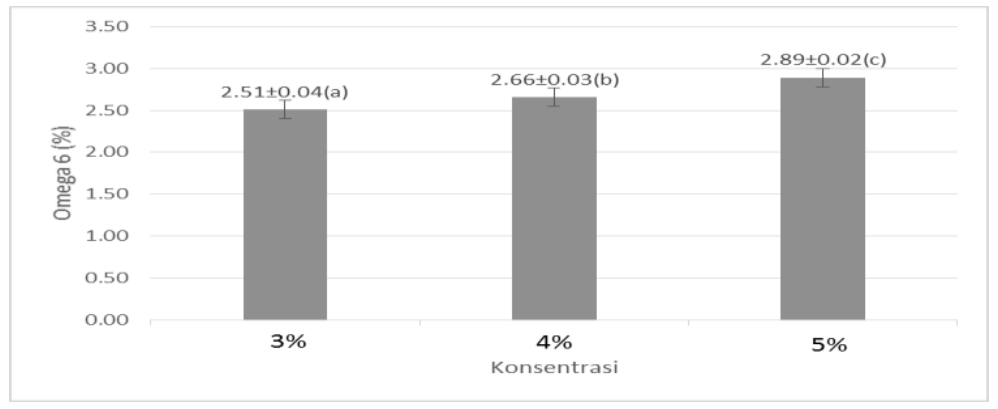

The value of omega 6 at 3\% grape seed oil concentration was $2.51 \%, 4 \%$ concentration was $2.66 \%$, and $5 \%$ concentration was $2.89 \%$. The highest omega 6 value was shown at a concentration of 5\% which was $2.89 \%$, while the lowest omega 6 was at a concentration of $3 \%$ at $2.51 \%$. Grape seed oil concentration treatment had a significant effect on omega 6 albumin powder. Grapeseed oil has a high omega 6 content. This content is higher than the results of omega 6 albumin powder. This is due to the heating process in the manufacture of albumin powder (Santoso, 2008). 
3.2 yield

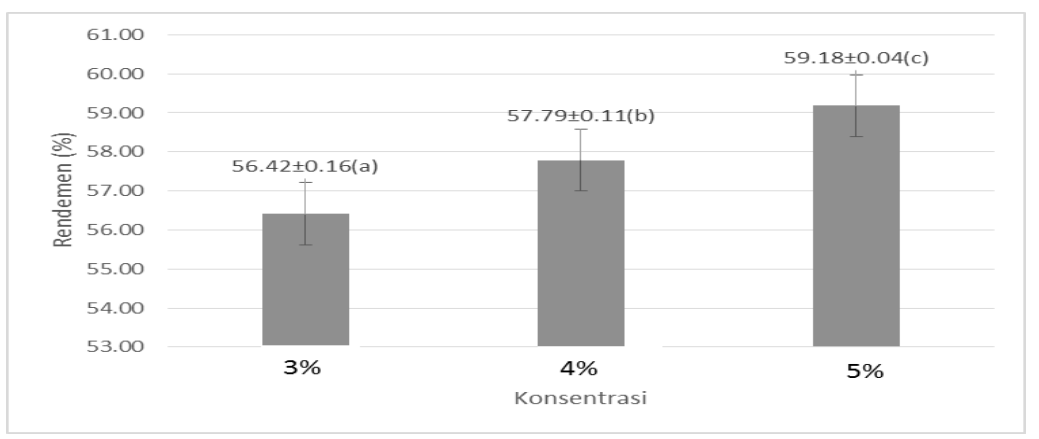

The yield of albumin powder with different concentrations of grapeseed oil resulted in different yield values. At 3\% grapeseed oil concentration, the yield was $56.42 \%$, $4 \%$ concentration was $57.79 \%$, and $5 \%$ concentration was $59.18 \%$. The yield is calculated using the gravimetric method, the yield calculation is carried out to determine the efficiency of the product manufacturing process. The addition of concentration treatment has a very significant effect on the powder (Rizal and Putri, 2014).

\subsection{Protein content}

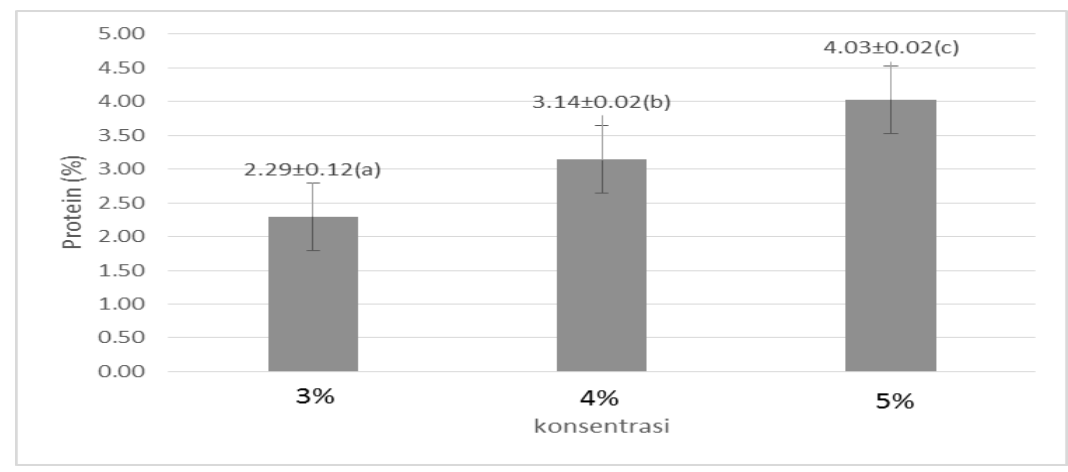

Protein content of albumin powder with different concentrations of grape seed oil resulted in different protein content. At a concentration of $3 \%$ grapeseed oil, the protein content was $2.29 \%$, the $4 \%$ concentration was $3.14 \%$, and the $5 \%$ concentration was $4.03 \%$.

\subsection{Fat Content}

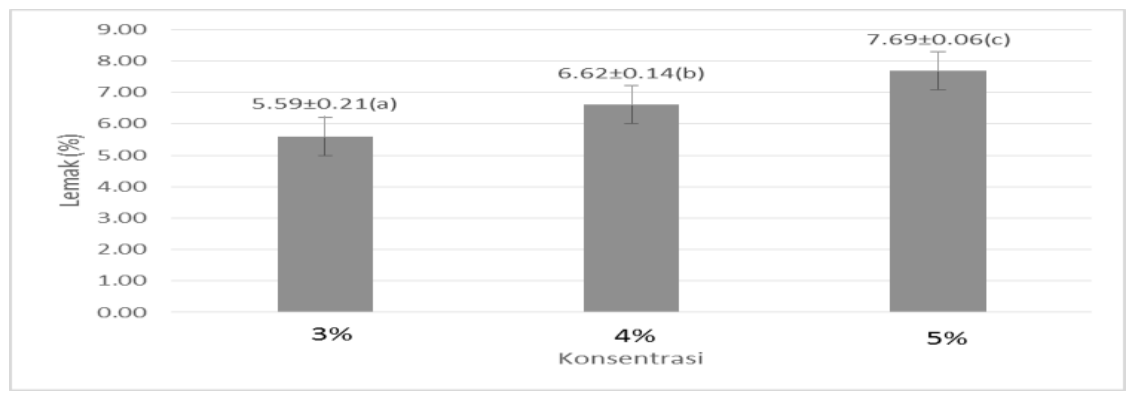

The fat content of albumin powder with different concentrations of added grape seed oil resulted in different fat content values. At 3\% grapeseed oil concentration, the fat content was 5.59\%, 4\% concentration was $6.62 \%$, and 5\% concentration was $7.69 \%$. The fat content produced in albumin powder comes from the addition of omega 6 and omega 3 . The source of omega 6 added oil is grape seed oil. Grapeseed oil has linoleic acid levels reaching 58-78\% (Ferdianto et al., 2016). 


\subsection{Water content}

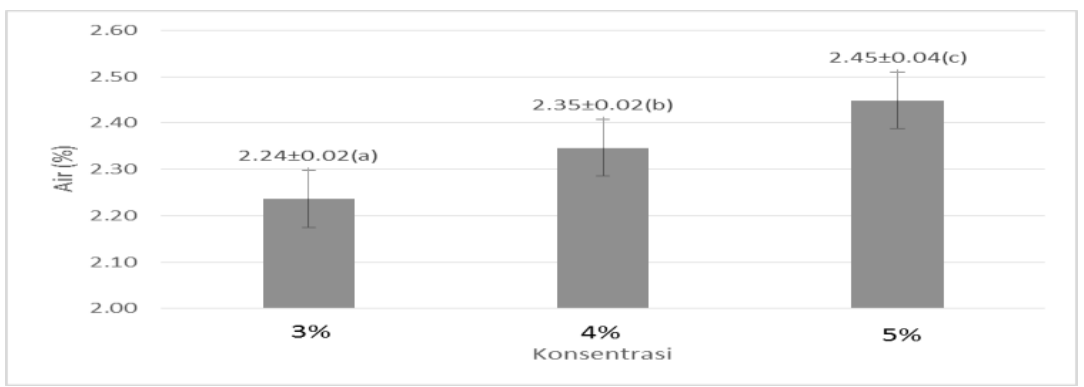

water content of albumin powder with different concentrations of grapeseed oil resulted in different water content. At a concentration of $3 \%$ grapeseed oil produced a water content of $2.24 \%$, a concentration of $4 \%$ of $2.35 \%$, and a concentration of $5 \%$ of $2.45 \%$. The addition of dextrin increases the total solids in the dried material, where the more fillers added will decrease the water content. (Utomo, 2013).

\section{Ash content}

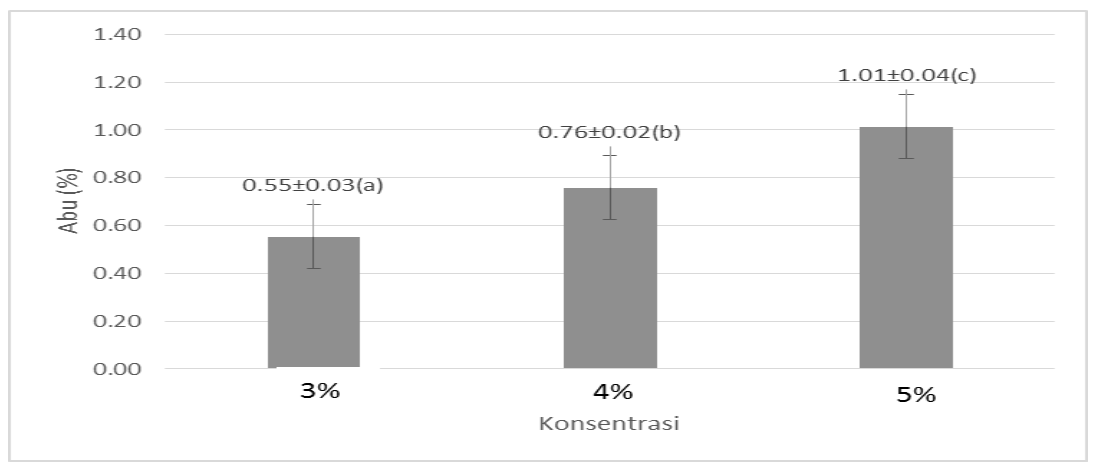

At a concentration of $3 \%$ grapeseed oil, the ash content was $0.55 \%$, the $4 \%$ concentration was $0.76 \%$, and the $5 \%$ concentration was $1.01 \%$. Ash is an organic substance, an organic waste residue from the combustion of an organic material. An increase in drying temperature causes an increase in ash content because with increasing temperature, the water content decreases so that a lot of residue is left in the material.

\subsection{Organoleptic assessment}

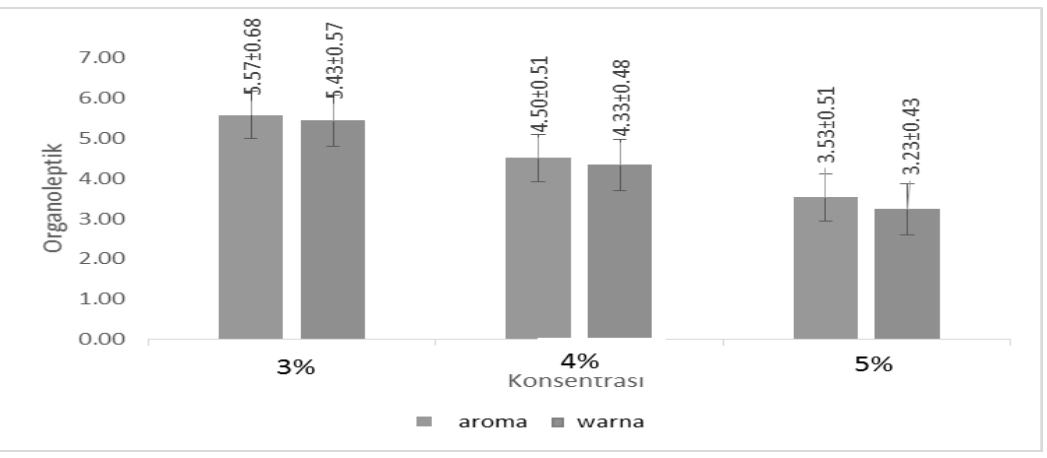

At a concentration of $3 \%$ grapeseed oil, the value of the aroma parameter shows a value of 5.57, a concentration of $4 \%$ of 4.50 , and a concentration of $5 \%$ of 3.53 . While in the treatment of grape seed oil concentration with a concentration of $3 \%$ the color parameter was 5.43 , the concentration of $4 \%$ was 4.33 , and the concentration of $5 \%$ was 3.23. In the color parameter, the highest value was obtained from the $3 \%$ grapeseed oil concentration of 5.43 and the lowest value from the 5\% grapeseed oil concentration was 3.23. The highest value in the color parameter indicates that the panelists do not like the color produced from albumin powder with the addition of grapeseed oil because it tends to be too yellow. As for the aroma parameter, the highest value was obtained from the 3\% grapeseed oil concentration of 5 . 


\subsection{Experimental animal testing}

After getting the best snakehead fish albumin powder with 5\% grapeseed oil concentration, compared to positive control $(\mathrm{K}+)$, the experimental animals were treated with commercial albumin powder, and the negative control (K-) was the experimental animals were injured but not given anything. Mice were injured on the back with a cut size of $2 \mathrm{~cm}$ and then treated every day. Wound closure was observed by measuring the injured area using a ruler on day 3 , day 5 , and day 7 , then the wound closure was recorded in $\mathrm{cm}$.

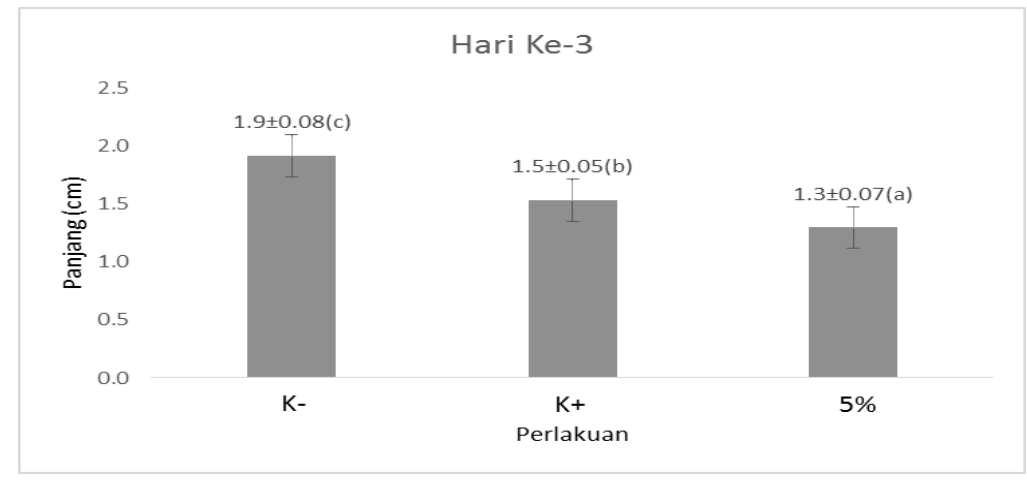

Results of wound closure on day 3

On the 3rd day different treatments showed different results of wound closure. The negative control treatment showed an average wound length of $1.9 \mathrm{~cm}$, the positive control treatment was $1.5 \mathrm{~cm}$, and the $5 \%$ albumin powder treatment was $1.3 \mathrm{~cm}$. The fastest wound closure on day 3 was obtained in the $5 \%$ albumin powder treatment, which was $1.3 \mathrm{~cm}$, while the longest wound closure was in the negative control treatment of $1.9 \mathrm{~cm}$. This means that the wound closure process in the best treatment on the 3rd day is $35 \%$.

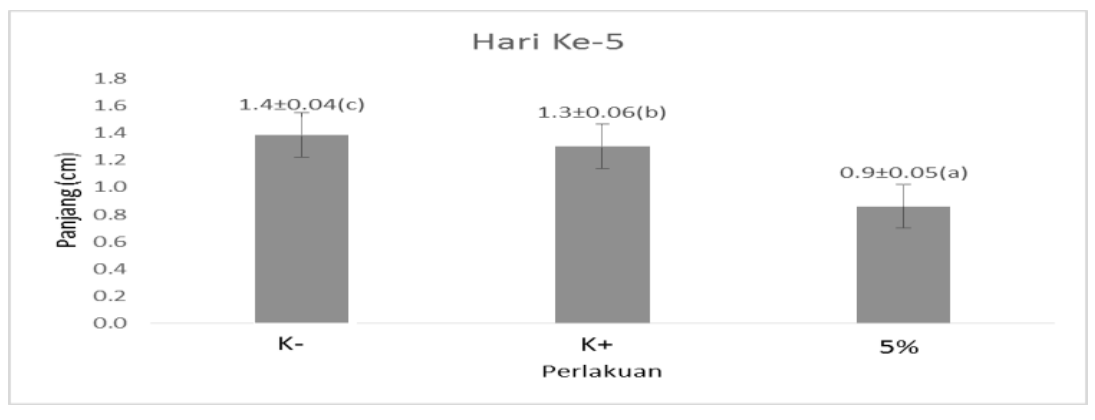

Results of wound closure on day 5

On the 5th day. The negative control treatment showed an average wound length of $1.4 \mathrm{~cm}$, the positive control treatment was $1.3 \mathrm{~cm}$, and the $5 \%$ albumin powder treatment was $0.9 \mathrm{~cm}$. The fastest wound closure on day 5 was obtained by treatment with $5 \%$ albumin powder, which was $0.9 \mathrm{~cm}$, while the longest wound closure was in the negative control treatment of $1.4 \mathrm{~cm}$. This means that the wound closure process in the best treatment on day 5 is $55 \%$. 


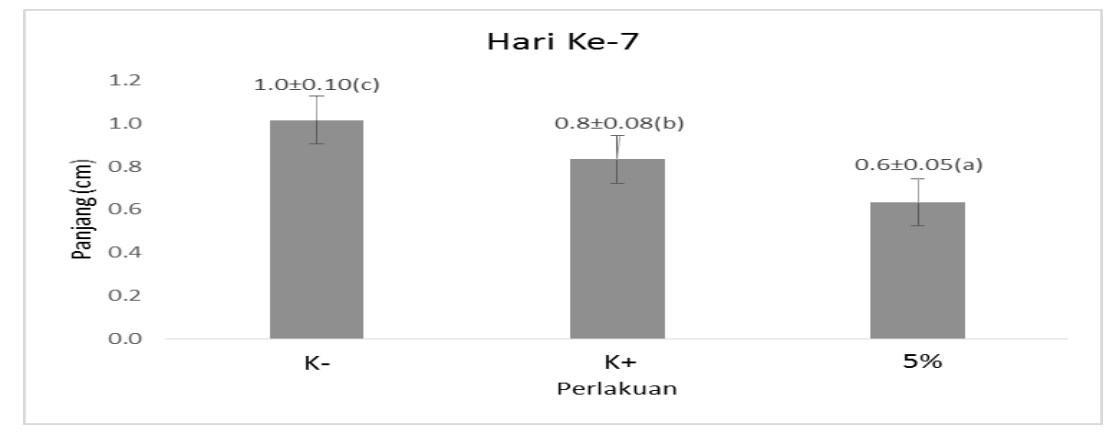

Results of wound closure on day 7

On day 7, the negative control treatment showed an average wound length of $1 \mathrm{~cm}$, the positive control treatment $0.8 \mathrm{~cm}$, and the $5 \%$ albumin powder treatment at $0.6 \mathrm{~cm}$. The fastest wound closure on day 7 was obtained by treatment with $5 \%$ albumin powder, which was $0.7 \mathrm{~cm}$, while the longest wound closure was in the negative control treatment of 1 $\mathrm{cm}$. This means that the wound closure process in the best treatment on the 7 th day is $70 \%$ 


\subsection{Fatty acid profile}

Albumin powder with the addition of grape seed oil at a concentration of $5 \%$ was analyzed for its fatty acid content to determine the type of the highest fatty acid after the addition of the concentration. The fatty acid profile of albumin powder is as follows.

\begin{tabular}{|ccc|}
\hline No. & Types of Fatty Acids & Rate $(\%)$ \\
\hline 1 & Linolenic Acid & 0.09 \\
2 & C 18:2 W6C (c-linoleic acid) & 2.88 \\
3 & C 18:1 W9C (c-oleic acid) & 1.22 \\
4 & C 20:5 w3 (eicosapentaenoic acid) & 0.02 \\
5 & C 17:1 (heptadekenoic acid) & 0.004 \\
6 & C 16:1 (palmitoleic acid) & 0.026 \\
7 & C 20:4 w6 (arachidonic acid) & 0.006 \\
8 & Omega 3 fatty acids & 0.13 \\
9 & C 24:0 (lignoceric acid) & 0.007 \\
10 & C 22:6 w3 (docosahexaenoic acid) & 0.011 \\
11 & C 18:0 (stearic acid) & 0.23 \\
12 & Omega 9 fatty acids & 1.22 \\
13 & C 15:0 (pentadecanoic acid) & 0.005 \\
14 & C 22:0 (behenic acid) & 0.003 \\
15 & C 14:0 (myristic acid) & 0.017 \\
\hline
\end{tabular}

The results of the fatty acid profile showed that the highest fatty acid in albumin powder with a concentration of $5 \%$ was linoleic acid at $2.88 \%$ and the lowest was behenic acid at $0.003 \%$. The addition of grapeseed oil adds fatty acid content, especially omega-6 which can affect the acceleration of wound closure.

\section{Conclusion}

Grape seed oil (Vitis vinifera) Concentration of 5\% is the optimal concentration that produces the best snakehead fish albumin powder including omega 6 of $2.89 \%$, protein content of $4.03 \%$, fat content of $7.69 \%$, ash content of $1.01 \%$, and yield of $59.18 \%$.

The results showed that the best treatment with negative control, positive control, and albumin powder with 5\% grape seed oil concentration on the wound had a significant effect on the wound closure process. On the 3rd day, 5th day, and 7th day of observation, the wound closure process was most effective in experimental animals treated with the best albumin powder with 5\% grapeseed oil concentration with $70 \%$ wound closure on the 7 th day. 


\section{References}

Suprayitno, E. 2014. Albumin Profile of Fish Cork (Ophiocephalus striatus) Of Different Ecosystems. International Journal of Current Research and Academic Review. 2(12): 201-208. ISSN: 2347-3215.

Silva, JR, B. Burger, CMC Kuhl, T. Candreva, MBP Dos Anjos. HG Rodrigues. 2018. Wound Healing and Omega-6 Fatty ISSN: 2456-8899

Yuniarti, DW, TD Sulistiyati, and E. Suprayitno. 2013. The Effect of Vacuum Drying Temperature on the Quality of Snakehead Fish (Ophiocephalus Striatus) Albumin Powder. Thpi Student Journal. 1(1): 1-9.

Santoso, H. 2008. Effect of heating and drying coconut flesh on free fatty acids in the manufacture of coconut flour. Journal of Agricultural Sciences. 4(2):154-160. ISSN:2723-4010

Rizal, D. and WDR Putri. 2014. Preparation of effervescent miana (Coleus (1) benth) powder: study of the concentration of dextrin and citric acid on the characteristics of Miana (Coleus (L) benth) effervescent powder. Journal of Food and Agroindustry. 2(4):.210-219. ISSN 2685-2861

Ferdianto, R., PH Riyadi and AD Anggo. 2016. Grape seed oil as an oiling agent in the tanning process of tilapia skin (Oreochromis niloticus) on physical quality. Journal of Fishery Products Processing and Biotechnology. 5(3):2731. ISSN : 2442-4145

Utomo. D., 2013. Preparation of mulberry (morus alba 1.) effervescent powder by studying maltodextrin concentration and drying temperature. Journal of Food Technology. 5(1): 49-69. ISSN : 2087 - 9679 